\title{
Evaluation of mating and the causes of noises at night in small dromedary camel herds
}

\author{
Mohamad Abdulmohsen ${ }^{1 *}$, Salah Abdulaziz Al-Shami', Saad Al-Sultan' and Marzouk Al-Ekna² \\ ${ }^{1}$ Department of Veterinary Public Health and Animal Husbandry, College of Veterinary Medicine, King Faisal University, Saudi Arabia, \\ ${ }^{2}$ Department of Clinical Studies, College of Veterinary Medicine, King Faisal University, Saudi Arabia
}

\section{A B S T R A C T}

\begin{abstract}
This study aims to evaluate the mating act in camel herds with a small female number and to determine the causes of noises and disturbances heard among the members at night during the breeding season. The proper sex ratio in the camel herds is one male for $50-80$ females, so the small number of females could not be sufficient for the intense desire of males during the short breeding season. The later situation worsens if more than one male exists within the herd members. The dominant males spent a longer time in mating $(P<0.01)$ than the submissive ones. The mating time increased $(P<0.01)$ if the females showed their readiness for copulation. The mating performance was successful if one male existed alone. The submissive male failed in performing intromission during the dominant presence. Improper sex ratio because of the small number of females did not satisfy the male desire. Therefore, the dominant male pretended to rest beside a preferred female at night in order to rape her through sudden mounting. Forced mating occurred by either coercion or deceiving the females. After mounting, the forced females tried to get rid of the males by biting his knee or face seriously. The behavioral responses of the forced females were the same whether they held down by the male or after tying their legs as many breeders do. During coercion, the male tried to fix her underneath by pressing her forearms. The later situation would probably end with improper intromission and in turn impaired reproduction.
\end{abstract}

Keywords: Dromedary camels; Breeding season; Forced mating; Less female number

\section{INTRODUCTION}

Camels are seasonal breeder animals that need special management practices to improve their reproductive behavior. One of the major problems in the breeding of the dromedary camels is the poor conception rate. The reproductive behavior of the one-humped camels is concentrated on the short breeding season in the winter (Al-Qarawi, 2005). The reproductive efficiency of the livestock depends mainly on hereditary factors, management practices and the production conditions (Kaufmann, 2005). The impaired camel reproductive efficiency under pastoral conditions had been recorded because of the short breeding season that did not enable the chance for frequent and successful mating (El - Hassanein 2003; Skidmore 2005 and Marai et al., 2009). The short breeding season, low male desire and aggressiveness were behind the impaired reproductive efficiency and injuries in camel herds (Padalino et al., 2015). Furthermore, the longer calving interval and higher abortion rate were among the causes of low fertility in the dromedary camels (Elwishy, 1987).
In Saudi Arabia and as the temperature lowers the mating time of the dromedary camels starts and continues from the end of October to the beginning of February. The mating time or duration of mating ranged from 9 to $22 \mathrm{~min}$ (Al-Hazmi, 2000). The mating time was shorter during the beginning of the breeding season than that during the peak of the season and decreased as the weather became warmer. The overall mean of copulation time was $5 \mathrm{~min} .37 \mathrm{sec} .+$ 0.1249 (Rai et al., 1987).

The female camel in the estrus would lie down to the male approach and camelids are the only ungulates that mate in the lying position (Rathore, 1986; Elwishy, 1988). If the female refused to lie down, the male would force her in many ways (Gauthier-Pilters and Dagg, 1981).

Unlike the females of other domestic animals, ovulation is conditioned by mating in she-camels (Elwishy, 1987). Therefore, some breeders forced the females into mating by restraining the forelegs. This was practiced to shorten

\footnotetext{
*Corresponding author:

Prof. Mohamad Abdulmohsen Mohamad, Professor of Animal Behavior and Management, Faculty of Veterinary Medicine, King Faisal University, Saudi-Arabia. Tel: +966548927792, E-mail: mmohamed@kfu.edu.sa
}

Received: 12 February 2018; $\quad$ Accepted: 24 June 2018; 
the calving interval and enhance the reproduction (Dioli, 1991 and Robert, 2010). In fact, mating was successful when females accepted the male willingly (Abdel Rahim and El-Nazier, 1993). On the other hand, after parturition by 4 days, male camels were observed forcing females for mating and all became pregnant (Khan and Younas, 2015). One adult male camel to 50:80 females was considered sufficient for the breeding purposes under nomadic conditions (Dioli, 1991 and Schwartz and Dioli, 1992). On the other hand, many camel herds in the Eastern region of Saudi Arabia contained less number of females that would not satisfy the intense desire of male. Meanwhile, Ahmed et al. (2018) reported the male to female ratio would not affect the reproductive efficiency in camels. Although one male camel is enough for 200 females, a smaller number of females are usually used safely without problems (Arthur et al., 1985).

This study aims not only to evaluate the mating act in camel herds with a small female number but also to determine the reasons of noises and troubles occurred among the members at night during the breeding season.

\section{MATERIAL AND METHODS}

This study was conducted on three private camel farms in the Eastern region of Saudi Arabia during two consecutive breeding seasons. The herd members on each farm were arranged equally to be 12 adults, apparently healthy camels ( 2 males and 10 females/farm). The age of camels on the three farms ranged from 6-8 years. The yard provided a minimum of $28 \mathrm{~m} 2$ of floor space area/adult (Higgins, 1986). The adult males joined the female yard on the three farms during the breeding seasons that continued from the end of October until the beginning of February.

\section{Observation and records}

The dominant male on each farm was identified as the only male who extruded the soft palate (gulla) during the rutting season. In addition, the dominance matrix (who supplanted whom in mating and feeding instances) was used in identifying the social rank of the herd members (Paul and Patrick, 2004). The copulation acts (either normal or forced mating) were targeted, where continuous observation sessions were planned to cover the 24 hours of the day on the three farms (each session continued 3 hours a day). The observation sessions covered the whole day i.e. the observation session started at $6: 45$ a.m. for 3 hours continuously, then the next observation session on the other day started at 9:45 a.m. and so on until covering the 24 hours of the day. The total observation hours were 72 ( 3 hours $\times 8$ sessions $\times 3$ farms). The way of forcing females into mating had been described. The latency from intromission until the withdrawal of penis was considered a duration of mating (Singh and Prakash, 1964). After the occurrence of mating, the time and duration ( $\mathrm{min}$ ) were recorded using a stopwatch. During resting, the females took a position similar to that of mating. The behaviors of males and females on each farm were recorded at the nighttime to investigate the causes of troubles (Table 1). Since most of the mating incidents were performed by the dominant male on the three farms, mating attempts were enabled for the submissive males after isolating the dominants in neighboring yards with visual communication. The couple during either mating or attempting mating was observed and photographed as mentioned in table 1.

\section{Experimental design}

Since the ovulation in camels is conditioned by coitus, some camel breeders tried to reduce the calving interval by forcing the females into mating through restraining their forelegs (Khan and Younas, 2015). Therefore, this experiment had been practiced on the three farms during two successive breeding seasons to evaluate the effects of female restraining on the mating performance. This experiment was also intended to investigate the performance of submissive male during the dominant presence and vice versa. Therefore, three adult females of nearly similar age (6.5-8 years) were restrained in a lying position for 30 min once weekly and exposed to the male once at a time. The submissive male on each farm attempted to mate one of the females 6 times once weekly as follows:

1. Three times while the dominant is watching, after isolation in the adjacent yard but with visual communication. The number of mating attempts was 9 on the 3 farms.

2. Three times performing alone, after complete isolation of the dominant (number of mating attempts was $9 / 3$ farms).

\begin{tabular}{|c|c|}
\hline Couple & Points of evaluation \\
\hline Male camel & $\begin{array}{l}\text {-The social rank of males. } \\
\text {-Smelling the female genital organs (p/a). } \\
\text {-Extrusion of gulla (soft palate) (p/a). } \\
\text {-Focusing during mating (without looking around) } \\
\text { or distracted (looking at the other male). } \\
\text {-Forelegs on the ground or over the female's } \\
\text { knee. } \\
\text {-Flexed knee joint or extended. } \\
\text {-Wrong and proper intromission. }\end{array}$ \\
\hline She-camel & $\begin{array}{l}\text {-Struggling underneath }(p / a) \text {. } \\
\text {-Grunting during mounting }(p / a) \text {. } \\
\text {-Orientation during intromission (p/a). } \\
\text {-Biting the male knee joint }(p / a) \text {. }\end{array}$ \\
\hline $\begin{array}{l}\text { Males at night } \\
\text { while resting of } \\
\text { females. }\end{array}$ & $\begin{array}{l}\text {-The male squats, without rumination besides } \\
\text { the preferred female and grinds his teeth (p/a). } \\
\text {-The male ruminates at rest and sleeps } \\
\text { later (p/a). }\end{array}$ \\
\hline
\end{tabular}

(p/a): Presence or absence of a behavioral activity 
The dominant male on each farm was given a chance to mate the restrained female 3 times only during the presence of the submissive male. The dominant had not been tried alone because he was successful and did not pay attention to the submissive presence. Mating time and the associated behavioral activities were observed for both males and restrained females.

\section{Ethical considerations}

This study follows the institutional guidelines for the humane treatment of animals and complies with the relevant legislation. The animal care committee at the Deanship of Scientific Research, King Faisal University had approved the female restraint to evaluate it, providing that some camel breeders have practiced it. The informed consent was taken from the breeders and considered by the animal care committee.

\section{Statistical analysis}

Means $( \pm \mathrm{SE})$ of mating time were determined for both dominant and submissive males and the independent samples T-test was used to test the significance between means (SPSS program version 24.0 (2016). Likewise, the means $( \pm S E)$ of the mating time were also determined when the females were receptive and/or forced, and the independent samples T-test was used to test the significant difference.

\section{RESULTS AND DISCUSSION}

During the two successive breeding seasons, the submissive males did not attempt mating except after isolation of the dominant in another yard. The dominant male was the only one who extruded the gulla (soft palate) on the three farms. The females showed their readiness for mating towards the dominant. The dominant males spent more time in mating $(\mathrm{P}<0.01)$ than the submissive ones while the mean frequency of ejaculation did not differ significantly between the dominant and submissive males (Table 2). The previous observation agrees with Perry (1985) who reported that the submissive ram mounted and ejaculated less when viewed by two dominant rams than when tested alone.

The short duration of copulation by the submissive males might be attributed to the fear-stress as they were looking to the dominants during their attempts. The submissive male did not perform the intromission properly because of the weak erection, and confusion (Figure 4). This could justify the shorter duration of mating because of the fear-stress during the act. The recorded mating times are nearly similar to Al-Hazmi (2000), while shorter duration was reported by Rai et al. (1987).

Forcing she-camels for mating occurred either by the male force or through restraining of females' forelegs. Eight cases were excluded out of 27 because of the intromission failure. Forcing the females by the male's force may be attributed to the less female numbers during the short breeding season. This disagrees with Ahmed et al. (2018) who reported that the male to female ratio did not affect the reproductive performance in dromedary camel herds.

The mating time increased $(\mathrm{P}<0.01)$ if the females showed their readiness for mating (Table 3). During mating, the forced females were struggling and trying to get rid of the male even by biting his knee joint (Figure 2). These findings agree with Mohamad et al. (2014) who observed that forcing the females decreased the mating time, and the forced females were struggling underneath to get rid of males. The receptive she-camels showed apparent behavioral signs indicating their acceptance and readiness to mate. She-camels in heat stand still to the male approach and may even mount the reluctant male (Figure 3). The peaceful environment created by receptive females was suitable for the occurrence of powerful erection that ensures successful mating (parasympathetic effect). Conversely, the stressful environment of the forced females resulted in the short time of mating (sympathetic effect).

The presence of one male in the herd resulted in the occurrence of successful mating without distraction. The presence of another male in the herd was stressful in the beginning because of both males engaged in watching each other away from the reproductive media. Therefore, the presence of another male could distract the other, especially during the breeding season until establishing the solid social structure. The effect of another male presence varied according to the social rank within the herd social structure. The dominant male performed mating without paying any attention to the submissive male. During the submissive male presence, the dominant was stable, showed strong erection (8/9), extended legs (8/9) and performed successful intromission all the time. On the other hand, the audience effect of the dominant male over the submissive was dramatic as he showed weak erection (8/9), flexed legs $(5 / 9)$ and performed improper intromission $(6 / 9)$.

Table 2: Means of mating time $(\mathrm{min})$ and frequency of ejaculation for both dominant and submissive male camels

\begin{tabular}{lcc}
\hline Male camels & Mating time & Frequency of ejaculation \\
\hline Dominant $(17)^{\mathrm{a}}$ & $13.50 \pm 0.95^{\star *}$ & $9.30 \pm 3.33$ \\
Submissive (10) & $7.29 \pm 0.69$ & $5.60 \pm 1.20$ \\
\hline
\end{tabular}

**Highly significant difference at $P<0.01$

a Number of observed cases

Table 3: Means of mating time $(\mathrm{min})$ in case of receptive females and after coercion

\begin{tabular}{lc}
\hline She-camels & Copulation time or duration \\
\hline Receptive (20) & $14.20 \pm 1.53^{\star \star}$ \\
Forced $(27)^{\mathrm{a}}$ & $8.40 \pm 0.98$ \\
\hline
\end{tabular}

${ }^{*}$ Highly significant difference at $\mathrm{P}<0.01$

${ }^{a}$ Number of observed cases 
The submissive male alone within the herd members had improved the mating performance as he became stable, showed strong erection and performed proper intromission in 7 cases out of 9 (Table 4). The possibility of copulation could occur in the daytime and at night as well. However, deceiving the females occurred only at night in the camel herds with a small female number, where the male lied beside the preferred female, then jumped suddenly over her in a mating trial (Figure 1). The noises heard at night was because of the excessive grunting emitted by the deceived

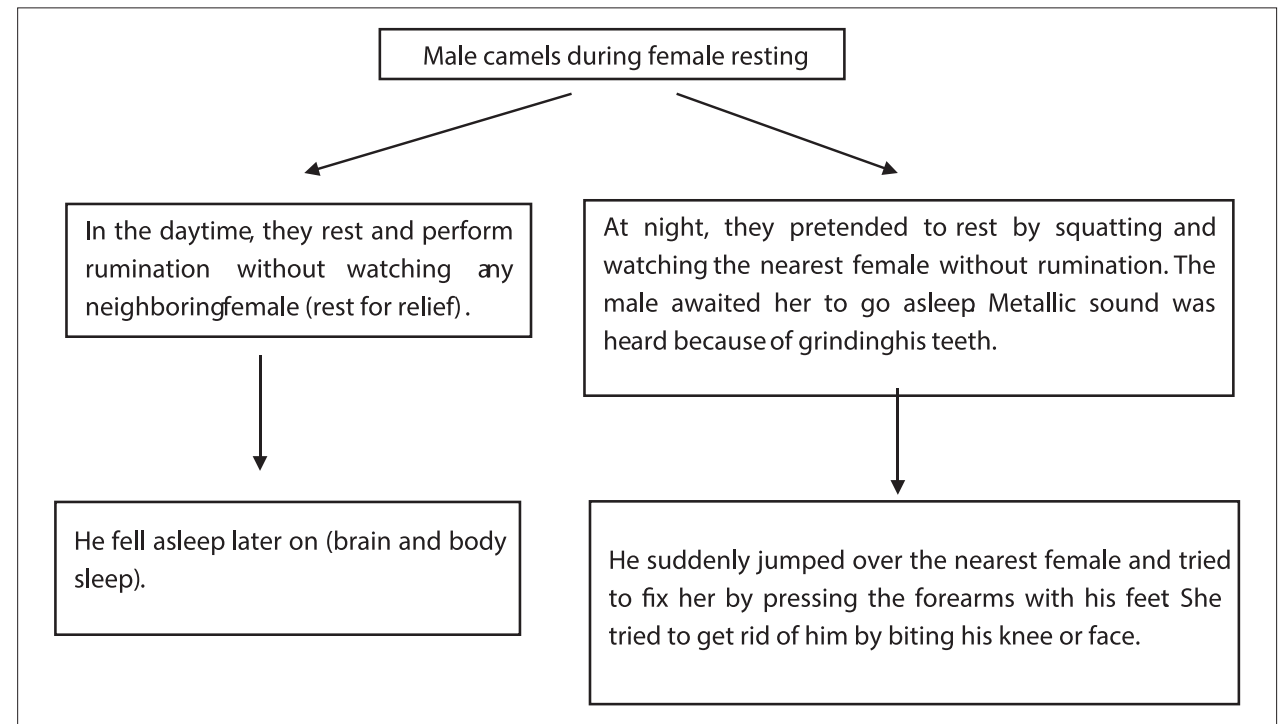

Fig 1. The behavioral responses of male camels during female resting in the daytime and at night.

Table 4: The behavioral characteristics of the dominant and submissive males during mating

\begin{tabular}{|c|c|c|c|c|c|c|c|c|}
\hline \multirow[t]{3}{*}{ Males } & \multicolumn{8}{|c|}{ Behavioral activities associated with the mating } \\
\hline & \multicolumn{2}{|c|}{ Before mounting } & \multicolumn{2}{|c|}{ Erection } & \multicolumn{2}{|c|}{ Forelimbs } & \multicolumn{2}{|c|}{ Intromission } \\
\hline & Distracted & focused & Weak & strong & Flexed & extended & proper & wrong \\
\hline Dominant $(9)^{a}$ & $0 / 9^{b}$ & $9 / 9$ & $1 / 9$ & $8 / 9$ & $1 / 9$ & $8 / 9$ & $9 / 9$ & $0 / 9$ \\
\hline Submissive (9) & $9 / 9$ & $0 / 9$ & $8 / 9$ & $1 / 9$ & $5 / 9$ & $4 / 9$ & $3 / 9$ & $6 / 9$ \\
\hline Submissive alone (9) & $0 / 9$ & $9 / 9$ & $0 / 9$ & $9 / 9$ & $2 / 9$ & $7 / 9$ & $7 / 9$ & $2 / 9$ \\
\hline
\end{tabular}

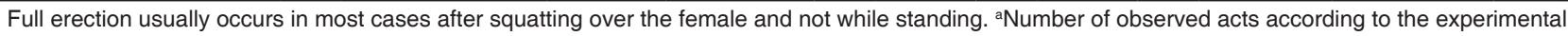
design on the 3 farms, b Number of item occurrence/total number of observed acts

Table 5: Timing and the behavioral responses during mating of receptive and forced females

\begin{tabular}{|c|c|c|c|}
\hline \multirow{3}{*}{$\begin{array}{l}\text { Time of mating and the } \\
\text { associated behaviors }\end{array}$} & \multicolumn{3}{|c|}{ She-camels } \\
\hline & \multicolumn{3}{|c|}{ Forced } \\
\hline & Receptive & Held down by the male & Deceived $^{*}$ \\
\hline \multicolumn{4}{|l|}{ Time of mating } \\
\hline In the daytime & + & + & - \\
\hline At night & + & + & + \\
\hline \multicolumn{4}{|l|}{ Males before mounting } \\
\hline Following the females & + & + & - \\
\hline Smelling female's genitalia & + & + & - \\
\hline Extruding the gulla (soft palate) & + & + & - \\
\hline Chasing the females & - & + & - \\
\hline Biting the female's stifle & - & + & + \\
\hline Lying down beside the females & - & - & + \\
\hline \multicolumn{4}{|l|}{ Males during intromission } \\
\hline Struggling & - & + & + \\
\hline Proper introduction & + & + & + \\
\hline Misdirection & - & + & + \\
\hline Feet position & On the ground & On the female's forearm & On the female's forearm \\
\hline \multicolumn{4}{|l|}{ Females after intromission } \\
\hline Struggling & - & + & + \\
\hline Vocalizing loudly & - & + & + \\
\hline Biting the male's face & + & + & - \\
\hline Biting the male's knee & - & + & + \\
\hline
\end{tabular}

+Means occurrence of a behavioral activity, ${ }^{*}$ Deceived female occurs by the male who pretended to rest beside her, waited for her sleep then jumped over suddenly in a mating trial 


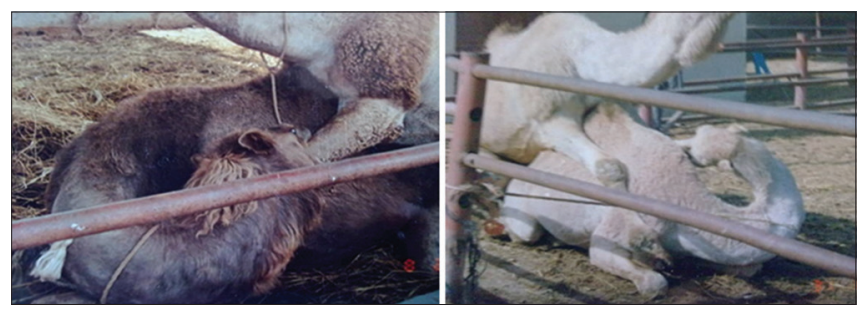

Fig 2. Forced females are biting the males' knee joints.

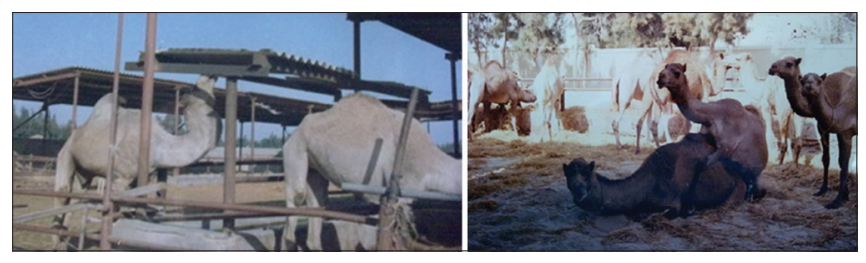

Fig 3. The receptive female stands still to the male (on the left) and covers the reluctant male expressing her desire for mating (on the right).

females (Table 5). These observations were inconsistent with Arthur et al. (1985) and Ahmed et al. (2018) who reported that the sex ratio and the smaller female numbers would not affect the reproductive efficiency in camel herds. The females that denied mating in the daytime would be forced into mating or deceived at night. Temporary alliance usually occurs between the compatible breeding pairs then gentle biting or kissing occurs without evil consequences. During mating, the forced or deceived females moved frequently, grunted loudly and tried to get rid of the males by biting his knee or face (Figure 2\&4). Thereby, improper intromission was recorded because of the females' lack of orientation and struggling while males were trying to fix them by pressing the females' forearms (Figure 4). The dominant male was focusing during mating the receptive female, with extended knee joint, and his feet were on the ground (Figure 5). The female was steady and enabled the proper intromission. The previous observations agree with Mohamad (1995).

\section{CONCLUSION}

In the small dromedary camel herds, the main cause of the noises heard at night is the sexual harassment of the deceived or forced females because of the unsatisfied male desire. Individual isolation of the male camels is necessary in case of small camel herds with a few female numbers. This would also help if the females were neither in heat nor pregnant. The receptive females should be taken individually to the male yard to enable peaceful mating. If the forced or deceived females were pregnant, the straining could lead to abortion. On the other hand, biting the knee joint could result in arthritis with its evil consequences.

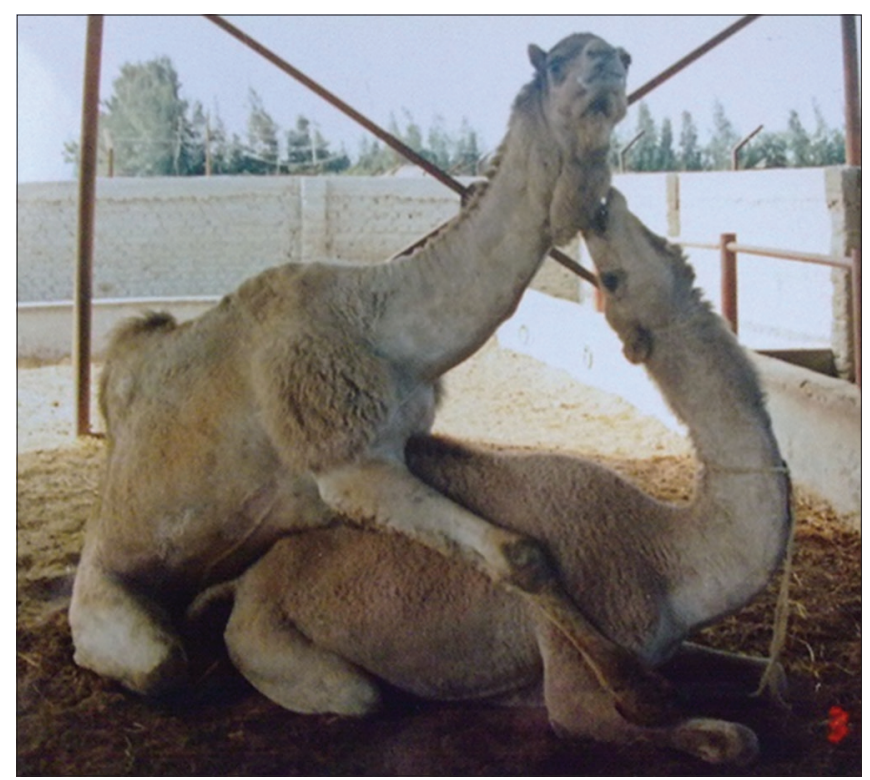

Fig 4. The male is trying to fix the forced female underneath.

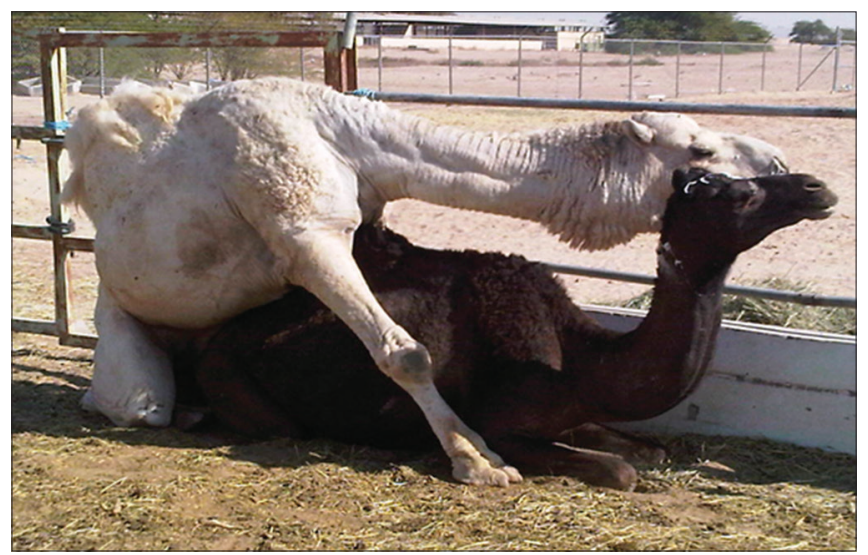

Fig 5. Focused male during mating of the receptive female (note the extended forelegs on the ground).

\section{ACKNOWLEDGEMENT}

The authors are thankful and would like to express their gratitude to the Deanship of Scientific Research, at KFU for the financial support given to the research project No: 140122.

\section{AUTHORS' CONTRIBUTION}

Mohamad Abdulmohsen formed the idea, participated in animal observation, designed the experiment and shared in writing the manuscript. Salah Abdulaziz Al-Shamiparticipated in the observation, performed the statistical analysis and shared in writing. Saad AlSultanparticipated in the observation, collected the data, and shared in writing. Marzouk Al-Ekna wrote the results andrevised the manuscript. 


\section{REFERENCES}

Abdel Rahim, S. E. A. and A. E. El-Nazier. 1993. Factors affecting camel reproductive performance in the tropics. Etudes Synth. IEMVT. 41: 131-147.

Ahmed, A., D. Derar, A. Abdulhadi, A. Assaf, K. Rashid, A. Tariq, A. Yaser and A. Fahd. 2018. Factors affecting reproductive performance in dromedary camel herds in Saudi Arabia. Trop. Anim. Health Prod. DOI: org/10.1007/s11250-018-1545-3.

Al-Hazmi, M. A. 2000. Mating behavioral aspects of one humped camel (Camelus dromedaries) in Jeddah province, Saudi Arabia. Saudi J. Biol. Sci. 7(2): 113-123.

Al-Qarawi, A. A. 2005. Infertility in the dromedary bull: A review of causes, relations and implications. Anim. Reprod. Sci. 87: 73-92.

Arthur, G. H., A. T. A. Rahim and A. T. Al Hindi. 1985. Reproduction and genital diseases of the camel. Br. Vet. J. 141: 650-659.

Dioli, M. 1991. Reproduction of camels in a traditional pastoral system in East Africa. In: Camel Newsletter No. (8). GTZ. Camel Extension Project. P.O. Box 47051 Nairobi, Kenya.

El-Hassanein, E. 2003. An Invention for Easy Semen Collection from Dromedary Camels. Available from: https://www.pdfs. semanticscholar.org/160a/57a/9af7a23a652c0da015a1226859 738d148.pdf.

Elwishy, A. B. 1987. Reproduction in the female dromedary (Camelus dromedarius): a review. Anim. Reprod. Sci. 15: 273-297.

Elwishy, A. B. (1988). Reproduction in the male dromedary (Camelus dromedarius): A review. Anim. Reprod. Sci. 17: 217-241.

Kaufmann, A. B. 2005. Reproductive performance of camels (Camelus dromedarius) under pastoral management and its influence on herd development. Livestock Prod. Sci. 92: 17-29.

Gauthier-Pilters, H. and A. I. Dagg. 1981. The Camel: Its Evolution, Ecology, Behavior and Relationship to Man. $1^{\text {st }}$ ed. Chicago University Press, Chicago and London.

Khan, N. and M. Younas. 2015. Reducing the calving interval in camel: Forced mating, a case study at camel breeding and research station, Rakh Mahni Punjab, Pakistan. Available from: https://www.academia.edu/918473/.

Marai, I. F. M., A. E. B. Zeidan, A. M. Abdel-Samee, A. Abizaid and A. Fadiel. 2009. Camel's reproductive and physiological performance traits as affected by environmental conditions. Trop. Subtrop. Agroecosyst. 10: 129-149.

Mohamad, M. A. 1995. Studies on Some Stress Factors Affecting the Behavior of Camels. PhD Thesis, Suez Canal University, Egypt.

Mohamad, M. A., S. A. Al-Shami, A. Marzouk, Al-Ekna and S. A. Al-Sultan. 2014. On Farm Evaluation of the Copulation act in Camels (Camelus dromedaries): Proceedings of the $48^{\text {th }}$ Congress of the International Society for Applied Ethology. Vitoria Gasteiz, Wageningen Academic, Spain, p. 154.

Padalino, B., D. Monaco and G. M. Lacalandra. 2015. Male camel behavior and breeding management strategies: How to handle a camel bull during the breeding season? Emir. J. Food Agric. 27(4): 338-349.

Paul, M. and B. Patrick. 2004. Measuring Behavior: An introductory Guide. $2^{\text {nd }}$ ed. Cambridge University Press, Cambridge, England.

Perry, G. C. 1985. Mating behavior. In: World Animal Science, A5. Ethology of Farm Animals. A Comprehensive Study of the Behavioral Features of the Common Farm Animals. Elsevier, Amsterdam-Oxford New York. pp. 325-332.

Rai, A. K., S. N. Tandon and N. D. Khanna. 1987. Copulation time of Bikaneri male camels. Indian J. Anim. Sci. 58(10): 1202-1203.

Rathore, G. S. 1986. Camels and their Management. $1^{\text {st }}$ ed. Indian Council of Agricultural Research, New Delhi.

Robert, I. 2010. Camel. Reaktion Books LTD., Illustrations.

Schwartz, H. J. and M. Dioli. 1992. The One-humped Camel in Eastern Africa. A Pictorial Guide to Diseases, Health Care and Management. Welker Sheim, F. R., Germany.

Singh, V. and A. Prakash. 1964. Sexual behaviour in camel. Indian Vet. J. 41: 475-477.

Skidmore, J. A. 2005. Reproduction in dromedary camels: An update. Anim. Reprod. 2(3): 161-171. 